\title{
BUBBLE FORMATION AND GROWTH
}

by

G. F. Berry

Components Technology Division
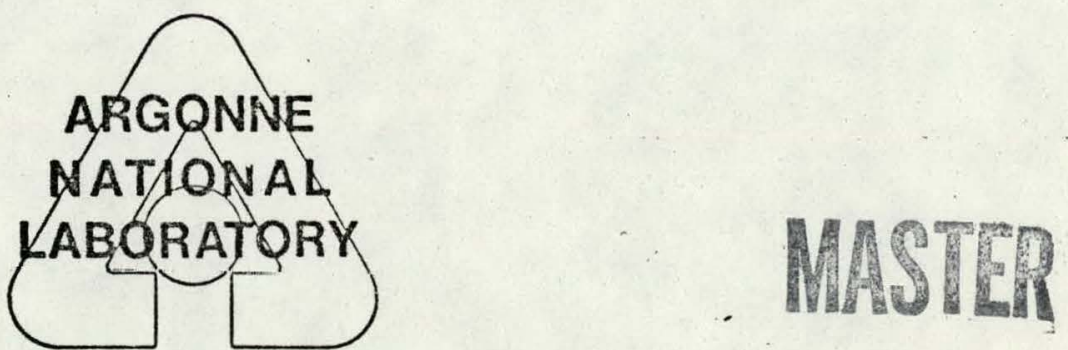

U of C-AUA-USAEC

NOTICE

This report was prepared as an account of work sponsored by the United States Government. Neither the United States nor the United States Atomic Energy Commission, nor any of their employees, nor any of their contractors, subcontractors, or their employees, makes any warranty, express or implied, or assumes any ear egal lability or responsibility for the accuracy, completeness or usefulness of any information, apparatus, product or process disclosed, or represents that its use would not infringe privately owned rights.

BASE TECHNOLOGY 


\section{DISCLAIMER}

This report was prepared as an account of work sponsored by an agency of the United States Government. Neither the United States Government nor any agency Thereof, nor any of their employees, makes any warranty, express or implied, or assumes any legal liability or responsibility for the accuracy, completeness, or usefulness of any information, apparatus, product, or process disclosed, or represents that its use would not infringe privately owned rights. Reference herein to any specific commercial product, process, or service by trade name, trademark, manufacturer, or otherwise does not necessarily constitute or imply its endorsement, recommendation, or favoring by the United States Government or any agency thereof. The views and opinions of authors expressed herein do not necessarily state or reflect those of the United States Government or any agency thereof. 


\section{DISCLAIMER}

Portions of this document may be illegible in electronic image products. Images are produced from the best available original document. 


\section{NOMENCLATURE:}

a bubble radius (in)

$a_{1}=$ initial bubble radius (in)

B. $=$ constant $23 /\left(9 g_{c} \rho_{1}\right)\left(\operatorname{in}^{3} / 1 b\right)$

b - exponential constant

$C=$ constant $\left(32 \mathrm{C}_{\mathrm{av}} / \mathrm{R}\right)$

$C_{\text {av }}=$ constant volume specific heat $\left(B T U / I b /{ }^{\circ} \mathrm{F}\right)$

$\mathrm{E}=$ energy / $1 \mathrm{lb}$ mass of water (BTU/1b)

e $\quad$ sodium Internal energy (BTU/1b)

$e_{1}=$ undisturbed sodium internal energy (BTU/Ib)

$\dot{8}_{c}=$ gravitational constant $\left(\right.$ in $\left./ \sec ^{2}\right)$

H $=$ heat of reaction (BTU/1b)

h = sodium enthalpy (BTU/1b)

$\mathbf{h}^{\circ}=$ steam reservoir enthalpy (BTU/1b)

$\mathrm{m}=$ mass of water (1b)

p = pressure (psia)

$p_{1}=$ sodium system pressure (psia)

$\mathbf{p}^{0} \quad$ - steani reservoir pressure (psia)

$p^{*}=$ critical choking pressure (psia)

R = hydrogen gas constant (BTU/1b/० F)

$r$ tube hole radius (In)

$I_{1}=$ Initial tube hole radius. (In)

$I_{\max }=$ maximum tube hole radius (in) 
NOMENCLATURE (Contd.)

$$
\begin{aligned}
& r_{c}=\text { control volume radius (In) } \\
& \mathrm{T}_{\text {ref }}=\text { undisturbed sodium temperature }\left({ }^{\circ} \mathrm{R}\right) \\
& t=\text { time }(\mathrm{sec}) \\
& \text { u. = sodium velocity (in/sec) } \\
& u_{0}=\text { isentropic compressibility function of wet steam (in/sec) } \\
& u_{c}=\text { control volume velocity (in/sec) } \\
& \nabla=\text { bubble volume }\left(\text { In }^{3}\right) \\
& p=\text { sodium density }\left(1 b-\sec ^{2} / \text { in }^{4}\right) \\
& \rho_{1}=\text { undisturbed sodium density }\left(1 b-\sec ^{2} / \operatorname{in}^{4}\right) \\
& p_{c}=\text { control volume density }\left(1 b-\sec ^{2} / \operatorname{in}^{4}\right) \\
& r=\text { time constant (sec) }
\end{aligned}
$$


ABSTRACT:

The objective of this subtask was to determine the sensitivity of various hydrogen bubble growth parameters to postulated formation conditions. This preliminary study concentrated on two aspects. of the problem which could have significant Impact on the formulation and numerical stability of an advanced sodium/water analysis system. These are the sensitivity of pressure and bubble radius to changes in the tube rupture model and the numerical stability of the solution to alternate assumptions concerning initial conditions for the governing differential equations:

As a reference solution, the ANL effort utilized the formulation and selected results contained in Zaker and Salmon [1] for unconstrained growth of a hemispherical bubble in incompressible sodium. After developing a numerlcal solution that could duplicate these results, a variable tube rupture rate was added to the model to determine its influence on the growth process. Parameter studies. showed that the bubble growth is sensitive to not only the time required for tube rupture but also to the tube rupture rate. These results will influence the bubble formation model to be incorporated in the advanced code by their implications concerning the characteristic time assoclated with the interaction of the bubble and the structure nearest to the fatlure position.

The study of alternate inftial conditions for the bubble growth model has resulted in Information on both the numerical stability of the solution method and on the length of time the solution is sensitive to the assumed 
Initial conditions. For example, it was found that, for times greater than $10^{-4}$ seconds, the evaluation of the bubble pressure is essentially unaffected by the initial conditions.

These results provide initial models to be incorporated in the first version of ANL's advanced code, delineate time scales to be considered in developing possible interaction effects to be treated by the code, and help in planning experiments to determine empirical relationships describing the inftiating event. 


\section{INTRODUCTION:}

To prepare for the development of a comprehensive analysis system treatIng large leaks in sodium heated steam generators and the effects of the resulting sodium-water reactions, ANL is engaged in the study of various preIiminary, code-related, development problems. The primary purpose of these preliminary studies is to provide background material prior to formulation of the analysis plan governing development of ANL's advanced'code.

A major concern regarding the effect of a steam generator tube rupture Is related to the mechanism by which such an event can compromise the structural Integrity of the generator and its contiguous piping system. Crucial to the analysis of such an event are possible differences in the sequence of events related to different rates of tube rupture. Tracting the progression of events through the system is a problem of great complexity and, hence, any simplifications that may result from isolated sensitivity studies which allow one to restrict the number of parameters. in the problem or reveal the range over which they have significant effect on later events are of great potential Interest in planning code development. The study of failure-rate effects is central to a fundamental understanding of the structural response of the system since such effects are intimately connected with the pressure history wthin the system and hence the damage potential of the event. The analysis to follow concentrates on one aspect of this problem: the sensitivity of hydrogen bubble growth and the resulting pressures to changes in the postulated Inftiating event. 
The topics that have received major attention in the bubble growth study are the effects of a model for tube rupture rates on the bubble formation process and the way in which initial conditions are reflected in subsequent bubble growth behavior. The basic bubble model assumes unconstrained expansion Into Incompressible sodium and does not include consideration of many possible physical processes which certainly have some effect on the growth process (e.g., water diffusion, multiple chemical reactions, etc.). This relatively simple model allows one to concentrate on the effect of rupture rate without having to first isolate the interaction of this rate with a multitude of other phenomena.

Prior to developing a method of analysis which could account for tube rupture rates, it was necessary to have an existing reference solution to use in the evaluation of parameter studies. The bubble formation and growth model described by Zaker and Salmon [1] provided both this needed reference and the theory used as the basis for developing rupture-rate dependent equations: The initial conditions used in [1] led to oscillation in the solution during the early phases of the growth. For this reason and because several alternate formulations of physically reasonable initial conditions are posstble, modified assumptions were developed to eliminate initial numerical instabilities. Further, a more sophisticated method of integrating the equations was used In the present analysis.

An outline of the model used in the study is given in the following section. This is followed by a brief summary of the results as 1llustrated 
: In the attached figures. Details concerning the numerical methods employed and extensive presentation of parametric results have not been included since the primary function of such material is to provide guidance to those working directly on code development. 


\section{ANALYSIS:}

Consider steam injection through a hole in flat plate into a volume of sodium. Let a denote the current value of the hemispherical reaction-product bubble radius. Let one fixed control surface be located at the break. Construct a fixed hemispherical control surface of radius $r_{c}$ in the moving but unreacted sodium concentric with the bubble. The overall mass balance for the system is

$$
\frac{d m}{d t}=2 \pi \frac{d}{d t} \cdot \int_{0}^{a} \rho r^{2} d r+2 \pi \frac{d}{d t} \int_{a}^{r} \rho r^{2} d r+2 \pi r_{c}^{2}(\rho u)_{c}
$$

Carrying out the indicated operations, letting the control surface radius, $r_{c}$, approach $a$, and introducing the hemispherical bubble volume $V$, one obtains

$$
\frac{d m}{d t}=\frac{d}{d t}(\rho V)-2 \pi a^{2} \rho_{c}\left(\frac{d a}{d t}-u_{c}\right):
$$

The energy balance for the system is

$$
\begin{aligned}
& \frac{d m}{d t}\left(h^{0}+H\right)=2 \pi \frac{d}{d t} \int_{0}^{a} \rho r^{2} d r+2 \pi \frac{d}{d t} \int_{a}^{r} c \\
& \rho\left(e+\frac{1}{2} u^{2}\right) r^{2} d r+2 \pi r_{c}^{2}\left[\rho u\left(h+\frac{1}{2} u^{2}\right)\right] c
\end{aligned}
$$

The material in the reaction-product zone is assumed to be at rest, and the zone is characterized by uniform internal energy, e, and other properties compatible with the equation of motion. Carrying out the indicated operations, letting $r_{c}$ approach $a$, and rearranging, one obtains 


$$
\begin{aligned}
& \frac{d m}{d t}\left(h^{0}+H\right)=\frac{d}{d t}(\rho V e)-2 \pi a^{2}\left[\rho\left(\frac{d a}{d t}-u\right)\right. \\
& \left.\left(e+\frac{1}{2} u^{2}\right)-p u\right]_{c}
\end{aligned}
$$

The steam Infection flow rate is a function of pressure in the reactionproduct zone. The formulae presented below represent approximate functional representation of results obtained from the rigorous instantaneous thermodynamic analyses as presented in reference (1).

$$
\begin{array}{ll}
\frac{d m}{d t}=\frac{d m^{*}}{d t} \sqrt{1-\left(\frac{p-p^{*}}{p^{0}-p^{*}}\right)^{2}} & \text { for } p^{*} \leq p \leq p^{0} \\
\frac{d m}{d t}=\frac{d m^{*}}{d t} & \text { for } p^{*} \geq p \\
\frac{d m}{d t}=0 & \text { for } p \geq p^{0}
\end{array}
$$

These equations can be modified to include the effect of variable tube hole openings by specifying $\frac{\mathrm{dm}^{*}}{\mathrm{dt}}$ such that

$$
\begin{array}{ll}
\frac{d m^{*}}{d t}=2 \pi x^{2}\left(g_{c} p^{*} u_{0}^{-1}\right) & \text { for } r \leq r_{\max } \\
\frac{d m^{*}}{d t}-2 \pi r_{w d x}^{2}\left(g_{c} p^{*} u_{0}^{-1}\right) & \text { for } r \geq r_{\max }
\end{array}
$$

where

$$
\begin{aligned}
& x=r \text { for } r<a \\
& x=a \text { for } a<r
\end{aligned}
$$

The varlable tube hole size vas determined using the following postulated equation: 


$$
r=r_{1}+\left(r_{\max }-r_{i}\right)\left(\frac{t}{\tau}\right)^{b} ; \ldots
$$

where $r_{1}, \tau$, and $b$ are essentially arbitrary constants.

The following equation was conservatively assumed to represent the cumulation effect of the various chemical reactions:

$$
2 \mathrm{Na}(1)+\mathrm{H}_{2} \mathrm{O}(1) \underset{1}{\longrightarrow} \mathrm{Na}_{2} \mathrm{O}(\mathrm{s})+\mathrm{H}_{2}(\mathrm{~g})+\mathrm{H}
$$

where $H$ is $32.6 \mathrm{kcal}$ (when $\mathrm{H}$ is referred to the standard equilibrium state of $77^{\circ} \mathrm{F}$ and $14.5 \mathrm{psia}$, the molar heat of reaction is reduced by $1.2 \mathrm{kcal}$ ).

The response of the surrounding incompressible fluid is represented by the standard energy equation,

$$
a \frac{d u}{d t}=\frac{p-p_{1}}{p_{1}}+\frac{1}{2} u^{2}-2 \frac{d a}{d t} u
$$

The above equation is applicable even if mass transfer occurs across the bubble boundary. In general $u \doteq \frac{d a}{d t}$ only when no mass is being consumed. Moreover, it should be noted that $\frac{d u}{d t}$ does not represent the acceleration of particles at the bubble boundary, except when $u=\frac{d a}{d t}$ and the surface moves with the fluid.

From equation (9). the mass of the reaction-products (sodium oxide and hydrogen) is given hy

$$
\rho \nabla=\frac{32}{9} \mathrm{~m}
$$

where $m$ is the mass of the injected steam.

The rate at which sodium is consumed (equation (2)) is therefore given by

$$
2 \pi a^{2} \rho_{c}\left(\frac{d a}{d t}-u_{c}\right)=\frac{23}{9} \frac{d m}{d t}
$$


For liquid sodium the total energy per unitimass $\left(e+\frac{1}{2} u^{2}\right)$ of the unreacted material at the bubble boundary can be replaced by the internal energy $e_{1}$ of the undisturbed sodium. In the reaction-product bubble; the internal energy is a function of temperature only. It is further assumed that the hydrogen in the product mixture behaves as a perfect gas, and the partial pressure of sodium monoxide in the mixture is negligible. Then,

$$
\begin{aligned}
& \frac{d}{d t}(\rho \nabla e)=\frac{d}{d t}\left[\frac{32 m}{9} c_{a v}\left(\frac{p}{\rho_{g}^{R}}-T_{r e f}\right)=\right. \\
& \frac{32 C_{a v}}{R} \frac{d}{d t}(p V)-\frac{32}{9} \frac{d m}{d t} c_{a v} T_{r e f}
\end{aligned}
$$

With the above simplifications the energy equation (equation (4))

becomes

$$
\frac{32 C_{\text {av }}}{R} \frac{d}{d t}(p V)=E \frac{d m}{d t}-2 \pi a^{2} p u
$$

where $\mathrm{B}$ is given by

$$
\mathrm{E}=\mathrm{h}^{0}+\mathrm{H}+\frac{32}{9} \mathrm{C}_{\mathrm{av}} \mathrm{T}_{\mathrm{ref}}+\frac{23}{9} \mathrm{e}_{1}
$$

If the density of sodium at the control volume, $p_{c}$, is replaced by the density of sodium in the undisturbed medium, $\rho_{1}$, then equation (11) becumes

$$
\frac{d a}{d t}=u+\frac{1}{2 \pi a^{2}} B \frac{d m}{d t}
$$

when $B=\frac{23}{9 p}$.

Equation (13) can be further simpliffed to 
10

$$
\left.\begin{array}{rl}
\ldots \frac{d p}{d t} & =\left(\frac{2}{3} \pi a^{3} c\right)^{-1}\left[(E-B C P) \frac{d m}{d t}-2 \pi a^{2}(1+C) p u\right.
\end{array}\right] \text { (16) }
$$

Therefore, equations (5), (6), (7), (9), (15), and (16) represent a set of first order ordinary differential equations which can be numerically solved in conjunction with one of the following sets of initial conditions:

I.) $p=p^{0}, u=0, a_{1} \leq r_{\max }$;

$$
\begin{aligned}
& \text { II.) } p=p_{1}, u=0, a_{i} \leq r_{\max } ; \\
& \text { III.) } \frac{d p}{d t}=0, u=0, a_{1} \leq r_{\max } ; \\
& \text { IV.) } \frac{d p}{d t}=0, \frac{d u}{d t}=0, a_{1} \leq r_{\max }
\end{aligned}
$$




\section{RESULTS:}

In most of the results to follow, the first order system of ordinary differential equations was solved using the initial conditions, IV. The effect of conditions I. through III. on the solution is shown in Fig. 3 and discussed below. All solutions were obtained by direct numerical integration using modifications of existing ANL subroutines based on the Bulirsch-Stoer iterative technique [2].

Fig. 1 gives a parametric representation of the effect of the time required for tube rupture on the pressure-radius relationship for the bubble. There appears to be a significant reduction in bubble pressure as a function of bubble radius for slower rupture times: This implies slow failures will produce lower pressure bubbles and, since the driving force causing bubble expansion is decreased, the time necessary for the bubble to reach the nearest adjacent structure will increase. Effects such as this are not modeled by simple cne-dimensicnal fiston-type bubble approximations and such models would tend to predict bubble-structure interactions occurring too early in the sodium-water reaction event.

Fig. 2 shows the effect of varylng the rate of tube rupture (exponent $b$, in eq. 7) for a constant fallure time, $\tau$, of $I$ ms. This figure indicates that bubble growth is not only dependent on fallure time but also upon faflure rate.

The results shown in Fig. 3 indicate the effect of various intial conditions on the pressure-time relationship for the case of instantaneous failure. These results are typical of the qualitative effect of varying the initial 
conditions and show that pressure is not sensitive to the assumed. Initial condition beyond a very brief period of adjustment (in this case, for $t>10^{-4}$ sec.). From results such as this, it was deduced that initial conditIon IV $\left(\frac{d p}{d t}=0, \frac{d u}{d t}=0\right)$ was the best choice since, in addition to yielding numerically stable solutions, the inftial velocity predicted by this condition was consistent with the maximur velocity derived in [1] using initial conditions. I. This maximum velocity was achieved before the bubble had measurably expanded.

The results indicated in Fig. 4 represent a study of different initial hole sizes. The smaller the initial hole size the quicker the bubble pressure diminishes. At a certain point in tinie $\left(\dot{n} \cong 2 \times 10^{-3}\right.$ sec.), the bubble pressure is no longer effected by the initial hole size.

Figs. 5 and 6 are presented to demonstrate the cumulative effect of a tube rupture process. The pressure impulse may be the best indicator of the damage potential of tube rupture. It is difficult to draw any definitive conclusions because an unconstrained tubble model cannot yield useful design Information beyond $t \cong 2 \times 10^{-4} \mathrm{sec}$. The results do, however, demonstrate in a limited manner, the effects of a representative tube ruptire process on bubble growth and indicate qualitative aspects of the problem that must be considered in development of the advancea socium-water reaction analysis coce. 


\section{REFERENCES:}

1. T. A. Zaker and M. A. Salmon, "Effects of Steam Tube Rupture in EBR-II Superheater," IITRI - 578T076-2 (September 1968)

2. ANL D255S - DFBND - DIFI, FORTRAN IV double precision routines which estimate the error in the Bulirsch-Stoer method for solution of a system of first order ordinary differential equations 


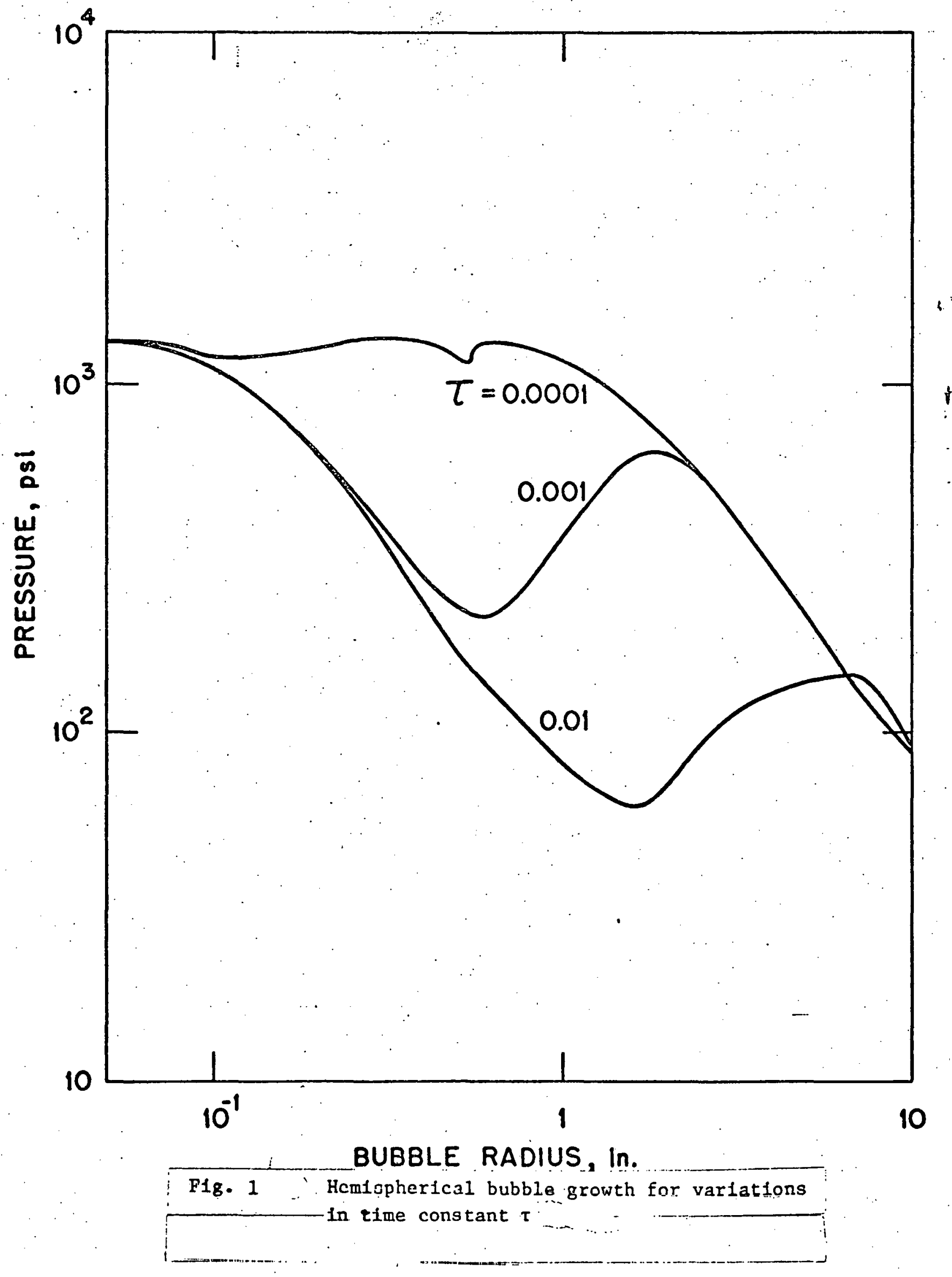




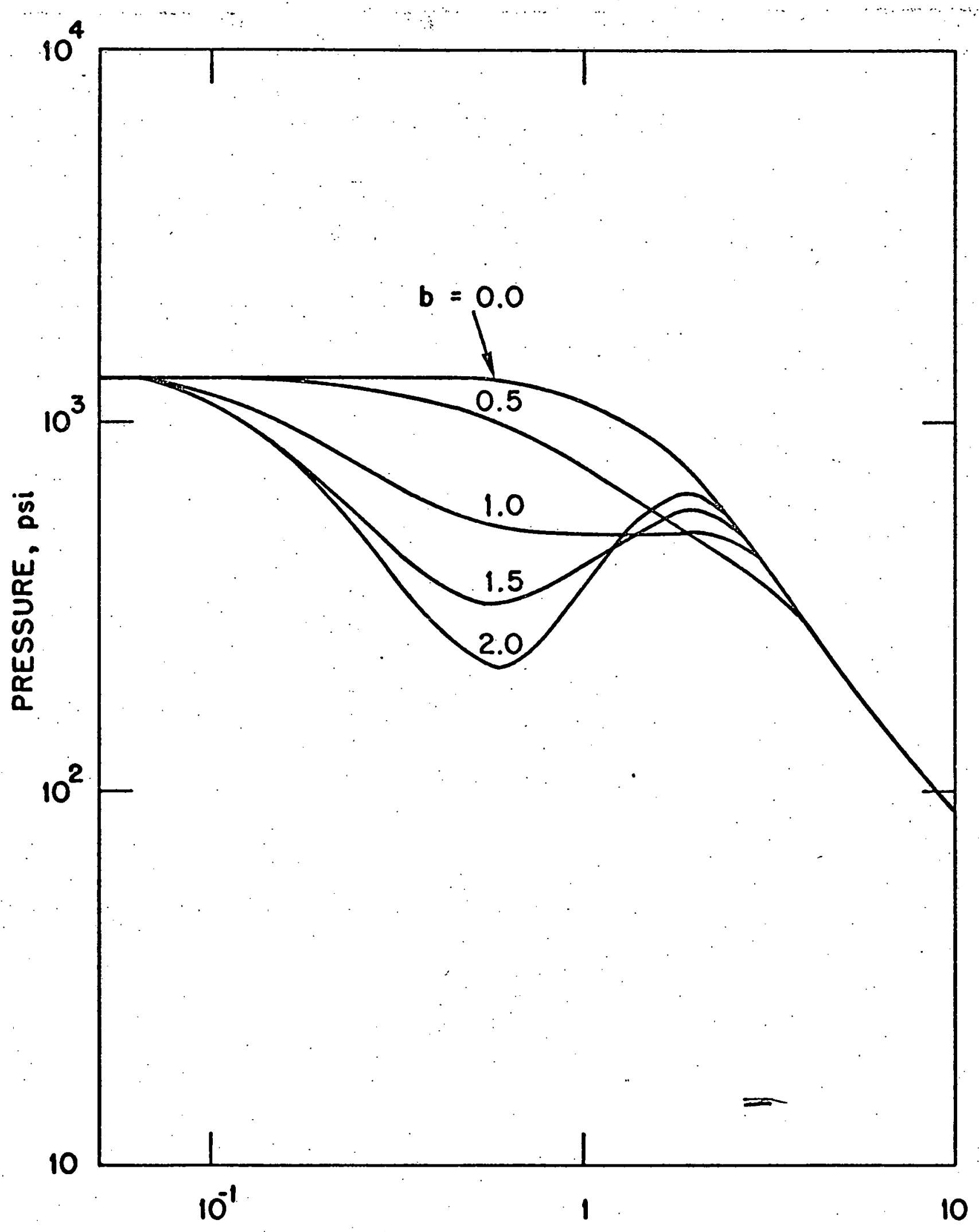

BUBBLE RADIUS in.

Fig. 2 - Hemispherical bubble growth for variations in exponent $b$ 


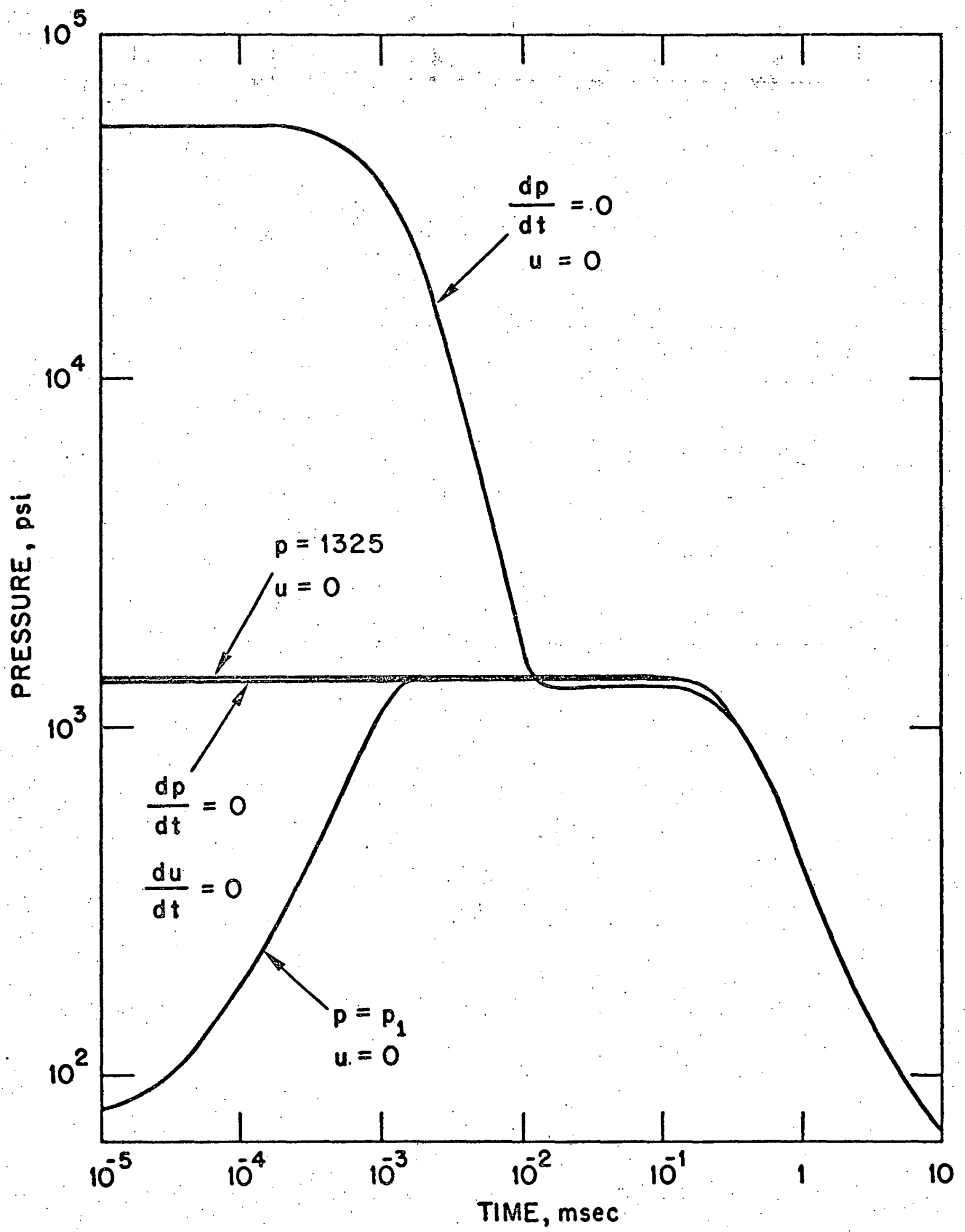

1.

F1g. 3 ... Hemispherical bubble growth for various initial conditions $\left(r_{1}=0.05\right)$. 


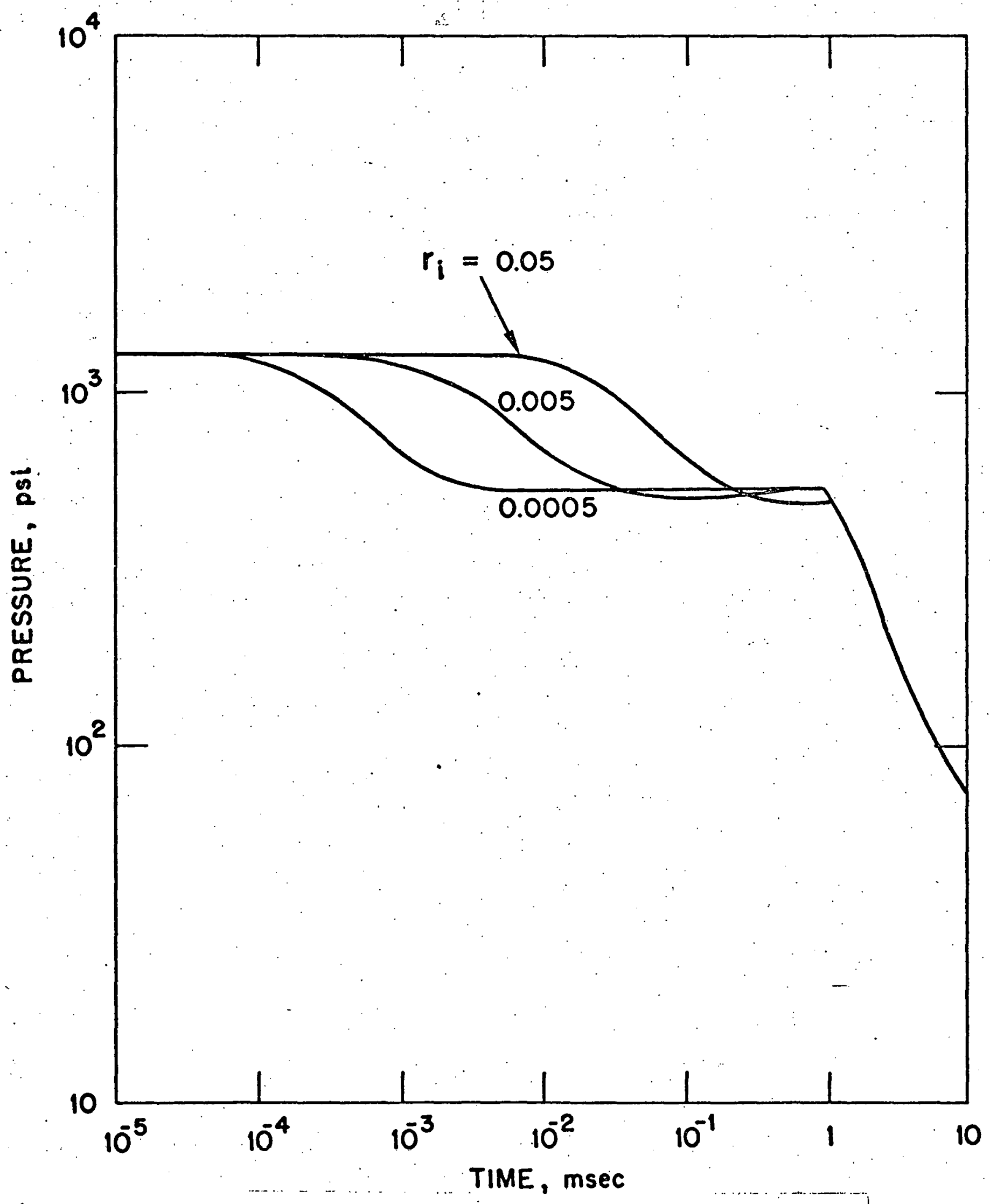

F1g. 4 Hemispherical bubble growth for various values of intial hole size. 


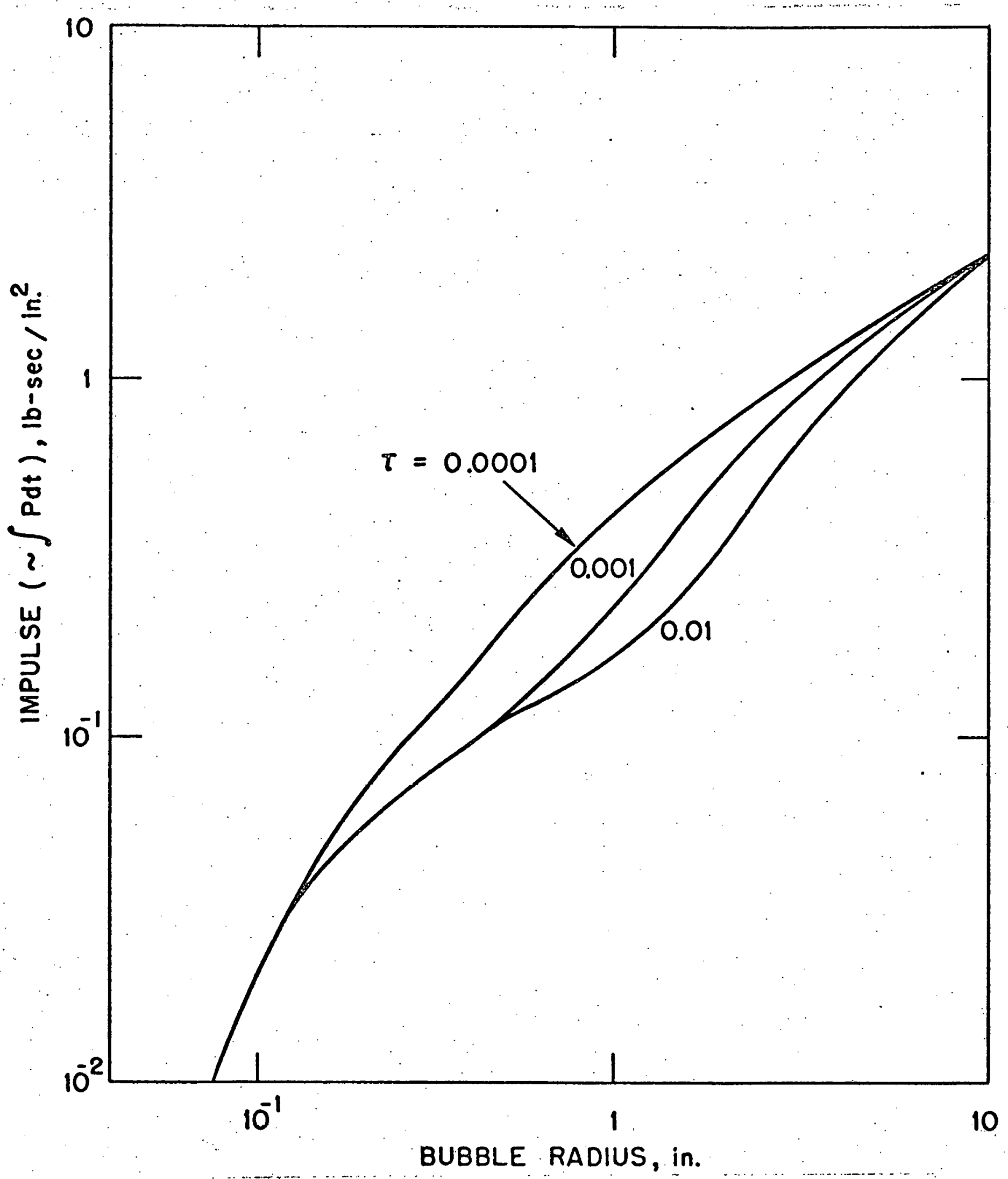

F18. 5 Hemispherical bubble growth damage potential for variations in time constant $\tau$ 


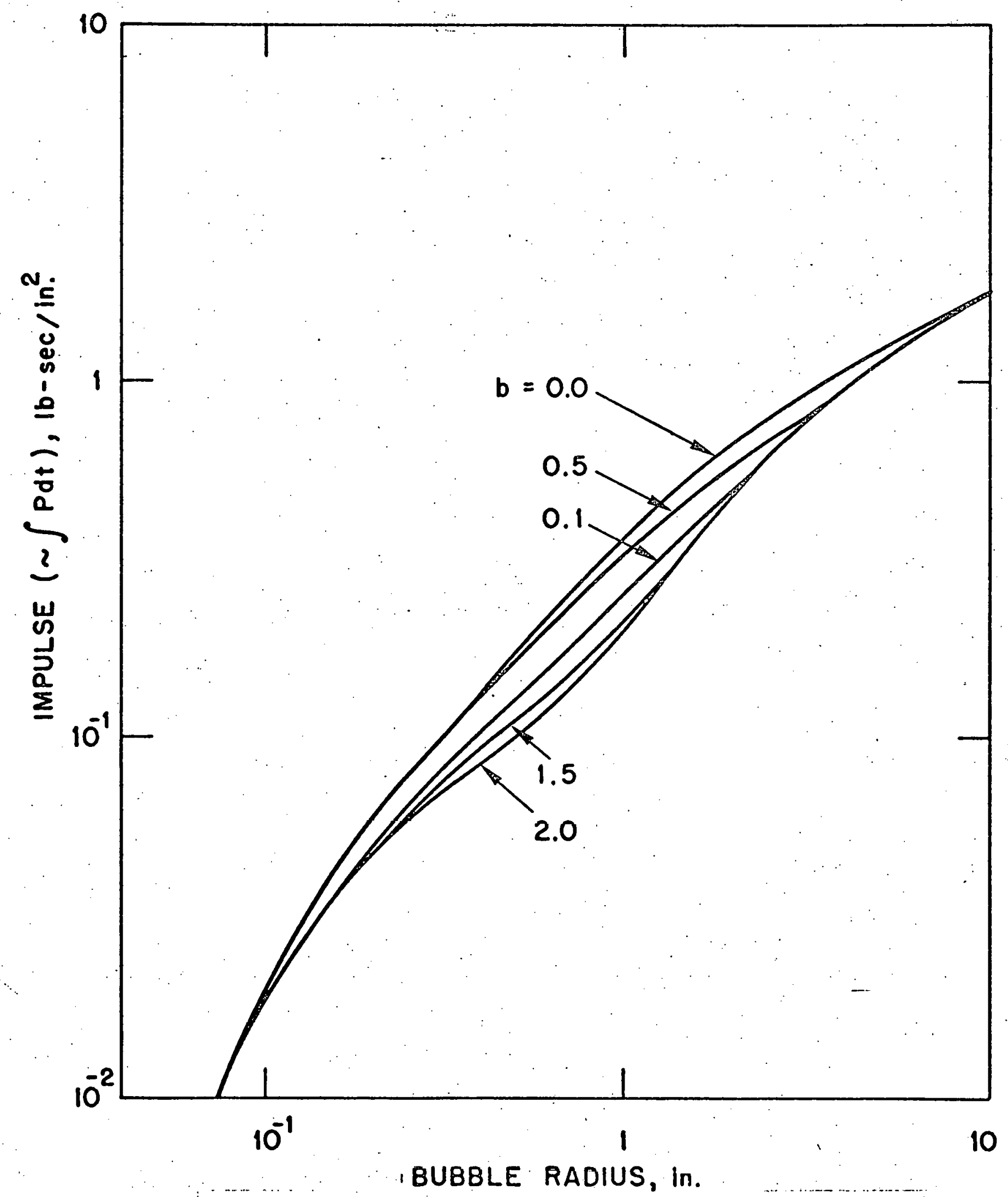

Fig. 6

Hemispherical bubble growth damage potential for variations in exponent $b$ 